\author{
INFO ARTIKEL \\ Riwayat Artikel: \\ Diterima : 10 Juni 2019 \\ Disetujui : : 15 Agustus 2019
}

\title{
GEOGRAFI
}

\section{ARAHAN KEBIJAKAN PENGGUNAAN LAHAN PERMUKIMAN BERBASIS BENCANA TSUNAMI DI KABUPATEN PESISIR SELATAN}

\section{Veni}

Jurusan Pendidikan Geografi, STKIP Pesisir Selatan. ( $\varangle)$ dakoaveni@gmail.com

\begin{abstract}
ABSTRAK
Penelitian ini didasarkan pada fenomena bencana tsunami yang berpotensi terjadi di Kabupaen Pesisir Selatan. Penelitian ini bertujuan untuk menentukan arahan kebijakan penggunaan lahan berbasis bencana tsunami di Kabupaten Pesisir Selatan yang dianalisis menggunakan teknik AHP (Analytical Hierarcy Process). menganalisis tingkat kesesuaian lahan untuk permukiman pada zona yang tidak beresiko tsunami dan mengetahui arahan kebijakan pengembangan permukiman penduduk berbasis bencana tsunami. Arahan kebijakan penggunaan lahan permukiman berbasis bencana tsunami di prioritaskan pada empat alternative kebijakan yaitu mitigasi bencana tsunami melalui pembangunan shelter dan jalur evakuasi, mengetahui zona resiko tsunami untuk pengembangan system peringatan dini, relokasi permukiman secara bertahap pada masyarakat yang bermukim pada kawasan beresiko tsunami dan menyusun kawasan peruntukkan lahan untuk permukiman berbasis bencana tsunami.
\end{abstract}

Kata Kunci : Kesesuaian Lahan, Permukiman, Tsunami

\section{PENDAHULUAN}

Beberapa penelitian terakhir mengindikasikan bahwa segmen Mentawai dari Megathrust Sumatera kemungkinan besar akan mengalami peruntuhan (rupture) dalam beberapa dekade ke depan, karena energi yang tertumpuk di lokasi ini sudah terlalu besar. Peruntuhan pada zona penunjaman ini dapat memicu gempabumi besar yang berpotensi menimbulkan kerusakan parah di sebagian besar kota-kota di Sumatera dan memicu bencana tsunami.

Kabupaten Pesisir Selatan merupakan wilayah pesisir yang berada di Pantai Barat Sumatera berbatasan langsung dengan Samudera Hindia dan zona tumbukan aktif dua lempeng (Indo-Australia dan Eurasia) menjadikan daerah ini salah satu daerah yang paling rawan bencana tsunami. Penduduk yang berada di Kabupaten Pesisir Selatan umumnya bermukim di daerah pesisir.
Luas permukiman yang ada di Kabupaten Pesisir Selatan sebesar 8.915,38 ha sekitar 1,54\% dari luas Kabupaten Pesisir Selatan yaitu 579.495 ha dengan jumlah rumah 105.997 rumah (Prasjaltarkim, 2013). Permukiman merupakan salah satu kebutuhan dasar manusia. Daerah bermukim umumnya mempunyai karakteristik tertentu yang harus terpenuhi. Sebagian wilayah permukiman ada yang berada di kawasan rawan bencana tsunami, sehingga tidak layak untuk dihuni.

Permukiman merupakan kebutuhan dasar manusia yang tidak dapat terelakkan. Semakin banyak penduduk semakin banyak pula kebutuhan lahan yang harus disiapkan untuk permukiman. Semakin sempitnya lahan yang sesuai untuk permukiman, maka dengan sendirinya lahan-lahan 
yang tidak sesuai dan rawan bencana akan menjadi alternatif untuk dijadikan lahan permukiman (Hermon, 2012:100).

Tingkat bahaya yang terjadi didaerah-daerah permukiman di sepanjang pantai dan pesisir, terutama pada pantai yang berhadapan langsung dengan zona tumbukan lempeng tektonik. Permukiman merupakan daerah yang paling penting dalam kegiatan mitigasi bencana alam, karena merupakan tempat tinggal dan tempat berkumpulnya penduduk. Kerugian terbesar akibat bencana umumnya terdapat pada daerah permukiman penduduk. Pemberian rekomendasi untuk lokasi pemukiman baru sangat dibutuhkan untuk meminimalkan resiko jangka panjang terhadap kelangsungan hidup masyarakat (Ula dan Azhari, 2013).

\section{METODOLOGI PENELITIAN}

Penelitian ini merupakan penelitian deskriptif dengan metode survei. Sampel diambil berdasarkan satuan bentuklahan dan ditentukan secara Stratified random sampling. Jadi Sampel dalam penelitian ini adalah 12 satuan bentuklahan yang dianggap mewakili daerah penelitian.

Data penelitian ini adalah data primer yang diperoleh langsung melalui pengamatan dilapangan yaitu mengenai drainase, kemiringan lereng, banjir, tekstur tanah, kedalaman efektif dan batuan kerikil dan erosi. Data sekunder didapat dari instansi terkait dan dari hasil sebelumnya berupa peta adminitrasi, peta lereng, peta jenis tanah, peta geologi, peta bentuklahan, peta penggunaan lahan, peta kawasan hutan, peta permukiman dan peta resiko tsunami. Penentuan penggunaan lahan permukiman pada zona beresiko tsunami dilakukan dengan analisis GISArcView 3.2 antara peta permukiman dan peta resiko tsunami.

Anaslis kesesuaian lahan permukiman pada zona yang tidak beresiko tsunami dilakukan dengan kriteria menurut USDA (1971) dimodifikasi Hermon (2012) yaitu ada tujuh kriteria kesesuaian lahan permukiman (drainase, kemiringan lereng, banjir, tekstur tanah, kedalaman efektif dan batuan kerikil dan erosi) yang kemudian dikaitkan dengan zona resiko tsunami. Arahan kabijakan pengendalian banjir yang dianalisis dengan menggunakan AHP (Analytical Hierarcy Process).

\section{HASIL DAN PEMBAHASAN}

a) Tingkat Kesesuaian Lahan untuk Permukiman pada Zona yang Tidak Beresiko Tsunami

Kesesuaian lahan untuk permukiman di Kabupaten Pesisir Selatan didasarkan pada parameter-parameter tingkat kesesuaian lahan untuk permukiman yaitu drainase, banjir, kemiringan lereng, tekstur tanah, batuan kerikil, kedalaman efektif tanah dan erosi.

Pengambilan sampel dilakukan pada 12 titik sampel yang dianggap dapat memiliki tingkat kesesuaian lahan yang sama. Hasil analisis parameter-parameter tingkat kesesuaian untuk permukiman menghasilkan dua zona tingkat kesesuaian lahan untuk permukiman di Kabupaten Pesisir Selatan. Zona tersebut terdiri dari zona yang sesuai untuk permukiman, lahan sesuai untuk permukiman dengan artian kemampuan lahan sangat baik dalam mendukung permukiman. Zona yang tidak sesuai untuk permukiman, lahan tidak sesuai untuk permukiman dengan artian kemampuan lahan dibatasi oleh sifat-sifat lahan yang tidak sesuai untuk permukiman.

\section{Tabel 1. Rekapitulasi Tingkat Kesesuaian Lahan untuk Permukiman pada setiap Satuan Bentuk Lahan}

\begin{tabular}{lcc}
\hline \multicolumn{1}{c}{$\begin{array}{c}\text { Satuan } \\
\text { Bentuklahan } \\
\text { (simbol) }\end{array}$} & $\begin{array}{c}\text { Kesesuaian } \\
\text { Lahan untuk } \\
\text { Permukiman }\end{array}$ & Ketinggian \\
\hline Lereng tengah (V4) & Sesuai & $70 \mathrm{~m}$ \\
Endapan lahar (V7) & Sesuai & $12 \mathrm{~m}$ \\
Bukit Intrusi (V27) & Sesuai & $75 \mathrm{~m}$ \\
Dataran aluvial (F1) & Sesuai & $10 \mathrm{~m}$ \\
Rawa belakang (F2) & Tidak sesuai & $4 \mathrm{~m}$ \\
Kipas aluvial (F10) & Sesuai & $15 \mathrm{~m}$ \\
Dataran banjir (F16) & Sesuai & $16 \mathrm{~m}$ \\
Pasir pantai (M9) & Sesuai & $2 \mathrm{~m}$ \\
Rawa pantai (M12) & Tidak sesuai & $2 \mathrm{~m}$ \\
Dataran pantai (M21) & Sesuai & $3 \mathrm{~m}$ \\
Bukit sisa (D13) & Tidak sesuai & $43 \mathrm{~m}$ \\
Blok pegunungan & Tidak sesuai & $45 \mathrm{~m}$ \\
tidak teratur (S1) & \\
\hline Sumber: Hasil Pengotahan Data Primer & 2014 \\
\hline
\end{tabular}

Sumber : Hasil Pengolahan Data Primer, 2014 
Kawasan yang sesuai untuk permukiman di Kabupaten Pesisir Selatan tersebar di hampir di seluruh Kabupaten Pesisir Selatan. Hampir seluruh wilayah Kabupaten Pesisir Selatan dapat digunakan untuk kawasan permukiman. Kawasan yang sesuai untuk permukiman juga berada pada kawasan TNKS dan hutan lindung sehingga dapat meyulitkan dalam pengembangan kawasan permukiman walaupun kawasan tersebut sesuai untuk permukiman.

Kawasan yang tidak sesuai untuk permukiman menyebar tidak dapat digunakan untuk pengembangan permukiman karena kondisi lahan yang dibatasi oleh sifat-sifat lahan yang tidak sesuai untuk permukiman.
Tabel 2. Luas Kawasan yang Sesuai dan Tidak Sesuai untuk Permukiman

\begin{tabular}{lc}
\hline $\begin{array}{c}\text { Kriteria Kesesuaian Lahan } \\
\text { untuk Permukiman }\end{array}$ & $\begin{array}{c}\text { Luas } \\
\text { (km) }\end{array}$ \\
\hline $\begin{array}{l}\text { Sesuai untuk permukiman } \\
\text { Tidak sesuai untuk } \\
\text { permukiman }\end{array}$ & 4007,225 \\
\hline
\end{tabular}

Sumber : Hasil Pengolahan Data Primer, 2014

Persebaran kesesuaian lahan untuk permukiman di Kabupaten Pesisir Selatan dapat dilihat pada peta kesesuaian lahan untuk permukiman Kabupaten Pesisir Selatan berikut ini.

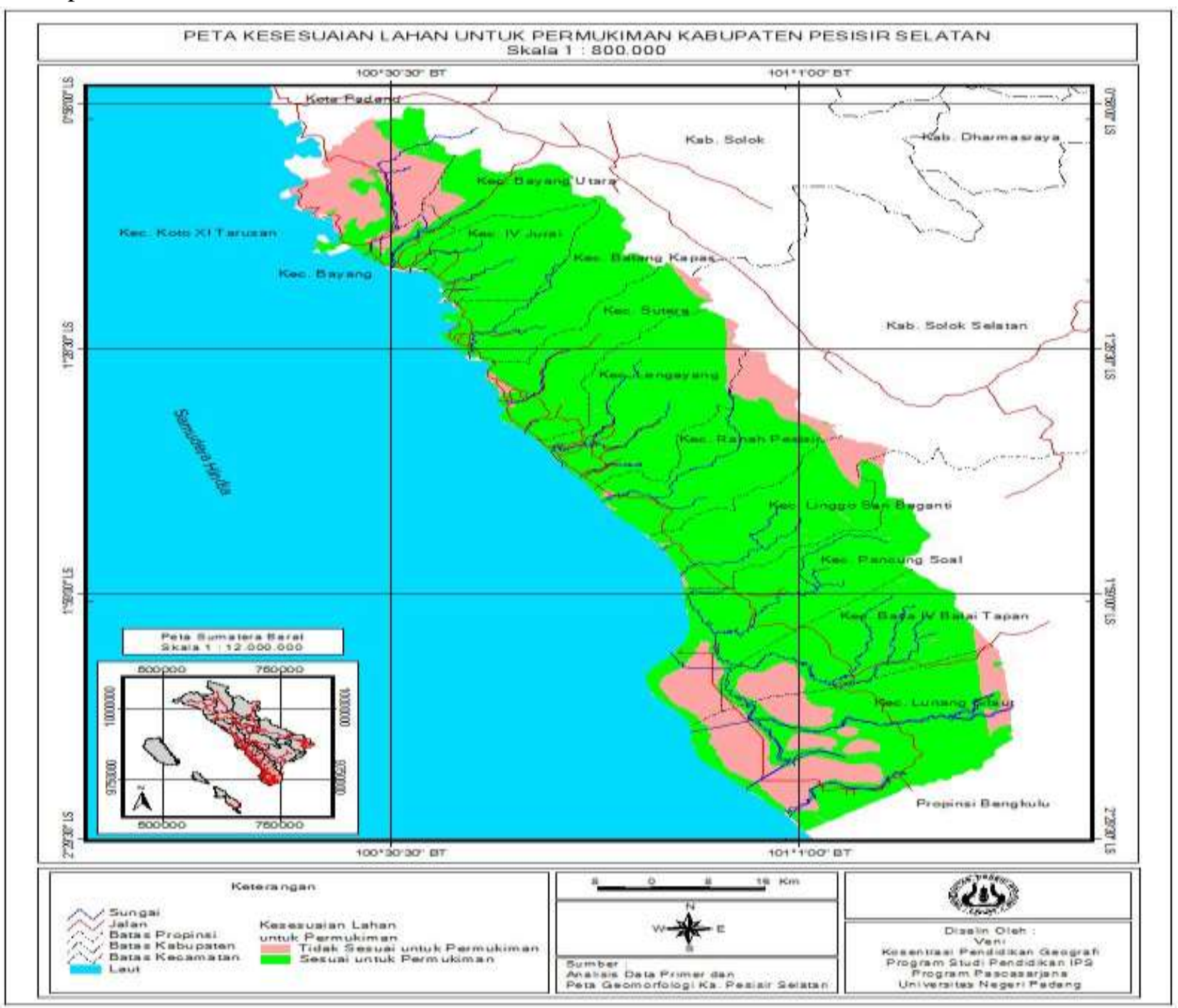

Gambar 1. Peta Kesesuian Lahan Permukiman

Distribusi kawasan untuk pengembangan permukiman pada kawasan beresiko tsunami dapat dilihat pada tabel 3 berikut ini : 
Tabel 3. Distribusi Kawasan Kesesuaian Lahan untuk Pemukiman

\begin{tabular}{|c|c|c|c|c|}
\hline No & $\begin{array}{c}\text { Kesesuaian } \\
\text { Lahan untuk } \\
\text { Permukiman }\end{array}$ & $\begin{array}{l}\text { Tingkat } \\
\text { Resiko } \\
\text { Tsunami }\end{array}$ & Luas (km) & Distribusi Kawasan \\
\hline 1 & Sesuai & Sedang & 946,036 & $\begin{array}{l}\text { Bagian selatan Kabupaten Pesisir Selatan dengan } \\
\text { penggunaan lahan hutan produksi dan hutan } \\
\text { lindung tepatnya di kec. Lunang Silaut dan Kec. } \\
\text { Basa IV Balai Tapan. }\end{array}$ \\
\hline 2 & Sesuai & Rendah & 3061,189 & $\begin{array}{l}\text { Bagian timur Kabupaten Pesisir Selatan yang } \\
\text { merupakan kawasan TNKS dan hutan lindung di } \\
\text { bagian utara tepatnya di Kec. Koto XI Tarusan. }\end{array}$ \\
\hline 3 & Tidak sesuai & Sedang & 838,710 & $\begin{array}{l}\text { Terdapat di bagian selatan Kabupaten Pesisir } \\
\text { Selatan pada kawasan hutan lindung dan areal } \\
\text { penggunaan lain. }\end{array}$ \\
\hline 4 & Tidak sesuai & Rendah & 903,954 & $\begin{array}{l}\text { Terdapat di Kabupaten Pesisir Selatan bagian } \\
\text { utara, Kec. Koto XI Tarusan, Kec. Bayang dan } \\
\text { Bayang Utara dengan penggunaan lahan hutan } \\
\text { lindung dan areal penggunaan lain. }\end{array}$ \\
\hline
\end{tabular}

a) Kawasan yang sesuai untuk permukiman dengan tingkat resiko tsunami sedang

Kawasan ini dapat digunakan untuk pengembangan permukiman yang tersebar di bagian selatan Kabupaten Pesisir Selatan namun pada kawasan ini harus ada upaya mitigasi bencana tsunami karena wilayah ini berada pada kawasan dengan resiko tsunami sedang. Daerah ini memiliki kemiringan lereng yang datar (0-8\%) serta ketinggian 0-25 mdpl.

b) Kawasan yang sesuai untuk permukiman dengan tingkat resiko tsunami rendah

Kawasan ini dapat dioptimalkan untuk pengembangan permukiman, karena relatif aman dari resiko tsunami. Kawasan ini tersebar di bagian timur Kabupaten Pesisir Selatan, hanya saja kawasan ini terkendala karena kawasan ini merupakan Kawasan Taman Nasional Kerinci Seblat (TNKS) dan hutan lindung di bagian utara Kabupaten Pesisir Selatan (Kec. Koto XI Tarusan).

c) Kawasan yang tidak sesuai untuk permukiman dengan tingkat resiko tsunami sedang

Kawasan ini tidak dapat digunakan untuk pengembangan permukiman. Selain karena tidak sesuai peruntukkannya untuk permukiman kawasan ini juga berada pada kawasan dengan tingkat resiko tsunami sedang. Kawasan ini terdapat pada bagian selata Kabupaten Pesisir Selatan.

d) Kawasan yang tidak sesuai untuk permukiman dengan tingkat resiko tsunami rendah

Kawasan ini tidak sesuai untuk permukiman namun memiliki tingkat resiko tsunami yang rendah. Apabila dilakukan pengembangan untuk permukiman kawasan ini, mungkin saja dapat dilakukan namun terdapat faktor-faktor penghambat/pembatas jika tetap dikembangkan sebagai kawasan permukiman dan hal ini akan menimbulkan kesulitan bahkan dapat menimbulkan bencana alam dan bencana sosial seperti banjir, tanah longsor, kelaparan dan konflik manusia dengan fauna. Persebaran kesesuaian lahan untuk permukiman berbasis bencana tsunami, dapat dilihar pada Peta Kesesuaian lahan untuk permukiman berbasis bencana tsunami berikut. 


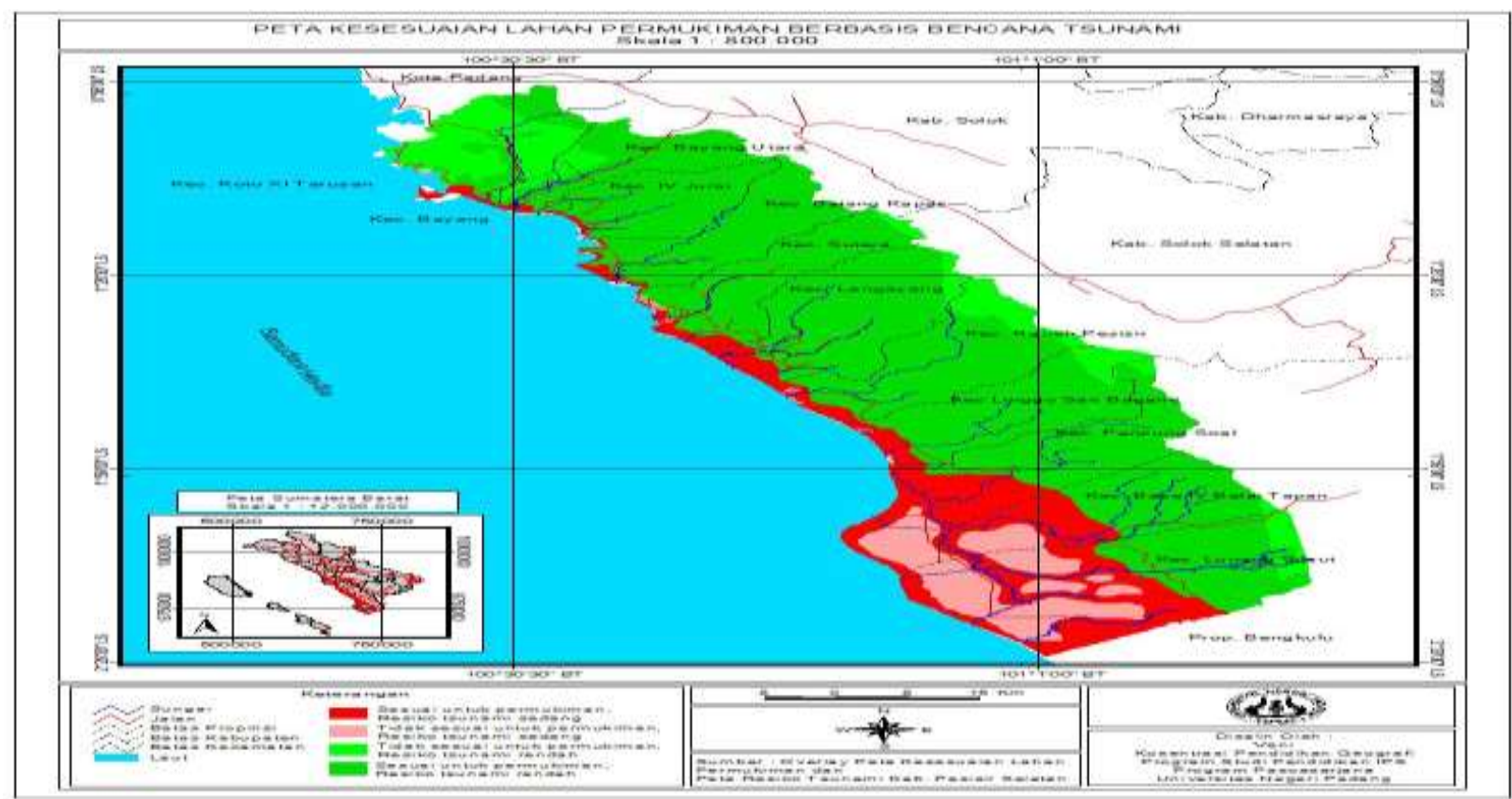

Gambar 2. Peta Kesesuaian Lahan Permukiman Berbasis Bencana Tsunami di Kabupaten Pesisir Selatan

Jika dikaitkan dengan kawasan hutan yang ada di Kabupaten Pesisir Selatan dimana sebagian besar dari wilayah Kabupaten Pesisir Selatan merupakan Kawasan TNKS dan hutan lindung. Kawasan lindung ini tidak dapat dilakukan untuk kawasan pengembangan permukiman karena kawasan ini digunakan untuk menjaga fungsi hutan. keseimbangan alam. Gangguan yang terjadi pada kawasan lindung dapat merusak hutan dan ekosistem. Menyusutnya populasi ekosistem hutan dapat menimbulkan kerugian besar bagi manusia. Berikut peta kesesuaian lahan permukiman berbasis bencana tsunami jika dikaitkan dengan

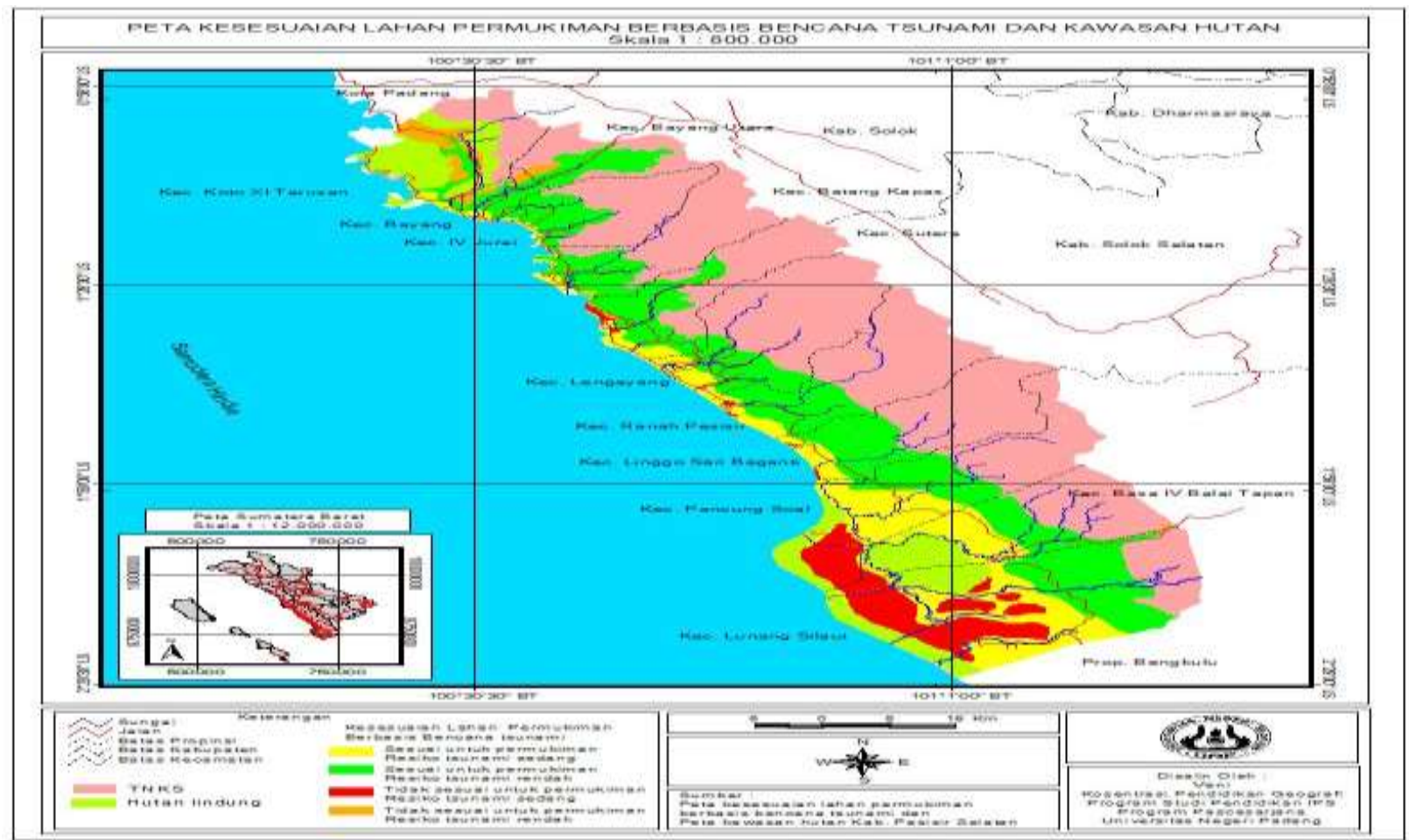

Gambar 3. Peta Kesesuaian Lahan Permukiman Berbasis Bencana Tsunami dan Kawasan Hutan di Kabupaten Pesisir Selatan 
Luas lahan yang sudah digunakan untuk permukiman pada kawasan yang sesuai untuk permukiman dengan tingkat resiko tsunami sedang adalah 58,234 km2 dengan luas keseluruhan 946,036 km2. Pada kawasan ini dapat dibangun permukiman hanya saja beresiko terhadap bahaya tsunami. Sedangkan untuk kawasan yang telah terbangun di perlukan upaya penanggulangan bencana tsunami.

Kawasan yang sesuai untuk permukiman dengan tingkat resiko tsunami rendah, luas lahan yang telah digunakan untuk permukiman adalah 26,37 km2 dari total luas keseluruhan 3061,189 km2 sehingga masih terdapat sekitar 3301,133 km2 dapat dioptimalkan untuk pengembangan permukiman. Namun sebagian besar kawasan ini merupakan TNKS.

Kawasan yang tidak sesuai untuk permukiman dengan tingkat resiko tsunami sedang, pada kawasan ini luas lahan yang telah digunakan untuk permukiman adalah $3,48 \mathrm{~km} 2$ dari luas kawasan 838,710 km2. Permukiman yang ada di kawasam ini perlu direlokasi secara bertahap karena kawasan ini selain beresiko terhadap bahaya tsunami, kemampuan lahannya juga dibatasi oleh sifat-sifat lahan yang tidak sesuai untuk permukiman.

Kawasan yang tidak sesuai untuk permukiman dengan tingkat resiko tsunami rendah. Luas permukiman yang ada pada kawasan ini adalah $89,1538 \mathrm{~km} 2$. kawasan ini memiliki resiko tsunami yang rendah, jika dilakukan tindakan pengembangan permukiman pada kawasan ini maka perlu mengatasi factor pengahambat/faktor pembatas yang menyebabkan kawasan ini tidak sesuai untuk permukiman. Untuk lebih jelasnya dapat dilihat pada tabel berikut ini.

Tabel 4. Kesesuaian lahan permukiman dan Kawasan Beresiko Tsunami

\begin{tabular}{|c|c|c|}
\hline Kawasan & $\begin{array}{l}\text { Luas } \\
\left(\mathbf{k m}^{2}\right)\end{array}$ & Keterangan \\
\hline $\begin{array}{ll}\text { Kawasan yang sesuai } \\
\text { untuk } & \text { permukiman }\end{array}$ & 946,036 & $\begin{array}{l}\text { Luas } \\
\text { kawasan }\end{array}$ \\
\hline $\begin{array}{l}\text { dengan tingkat resiko } \\
\text { tsunami sedang }\end{array}$ & 58,234 & $\begin{array}{l}\text { Telah } \\
\text { digunakan }\end{array}$ \\
\hline
\end{tabular}

\begin{tabular}{|c|c|c|}
\hline $\begin{array}{l}\text { Kawasan yang sesuai } \\
\text { untuk permukiman } \\
\text { dengan tingkat resiko } \\
\text { tsunami rendah }\end{array}$ & 3061,189 & $\begin{array}{l}\text { Luas } \\
\text { kawasan } \\
\text { Telah } \\
\text { digunakan }\end{array}$ \\
\hline $\begin{array}{lr}\text { Kawasan yang tidak } \\
\text { sesuai } & \text { untuk } \\
\text { permukiman dengan } \\
\text { tingkat resiko tsunami } \\
\text { sedang }\end{array}$ & 838,710 & $\begin{array}{l}\text { Luas } \\
\text { kawasan } \\
\text { Telah } \\
\text { digunakan }\end{array}$ \\
\hline $\begin{array}{lr}\text { Kawasan yang tidak } \\
\text { sesuai } & \text { untuk } \\
\text { permukiman dengan } \\
\text { tingkat resiko tsunami } \\
\text { rendah }\end{array}$ & 903,954 & $\begin{array}{l}\text { Luas } \\
\text { kawasan } \\
\text { Telah } \\
\text { digunakan }\end{array}$ \\
\hline \multicolumn{3}{|c|}{ Sumber : Pengolahan Data Primer, 2014} \\
\hline $\begin{array}{l}\text { Arahan Kebija } \\
\text { Permukiman Pend }\end{array}$ & $\begin{array}{l}\text { an } \\
\text { uk B }\end{array}$ & sis Bencan \\
\hline
\end{tabular}

Arahan kebijakan pengembangan permukiman penduduk berbasis becana tsunami di daerah penelitian dirumuskan dari hasil-hasil penelitian yang telah dilakukan, sehingga diperoleh berbagai alternatif kebijakan pengembangan permukiman penduduk berbasis bencana tsunami yang ditinjau dari 3 aspek, yaitu:

(1) permukiman pada zona beresiko tsunami,

(2) tingkat kesesuaian lahan untuk permukiman, dan

(3) peruntukan lahan.

Setelah dianalisis dari ketiga kriteria kebijakan pengembangan permukiman penduduk berbasis becana tsunami diperoleh kriteria yaitu permukiman pada zona resiko tsunami $(0,5578701)$, kesesuaian lahan untuk permukiman $(0,2241723)$ dan peruntukan lahan $(0,2179576)$. Alternatif kebijakan dalam evaluasi penggunaan lahan permukiman berbasis bencana tsunami di Kabupaten Pesisir Selatan diprioritaskan sebagai berikut:

a) Mitigasi bencana tsunami melalui pembangunan shelter dan jalur evakuasi.

b) Mengetahui zona resiko tsunami untuk pengembangan sistem peringatan dini.

c) Relokasi Permukiman secara bertahap pada masyarakat yang bermukim pada kawasan yang memiliki resiko tsunami dan 
d) Menyusun kawasan peruntukan lahan untuk permukiman yang berbasis bencana tsunami.

Permukiman berbasis bencana tsunami perlu diterapkan di Kabupaten Pesisir Selatan, hal ini di nilai dapat mengurangi kerugian yang diakibatkan oleh bencana tsunami sesuai dengan perencanaan tata ruang (spatial plan) yang memiliki tujuan untuk menghasilkan penggunaan ruang yang efisien, termasuk diantaranya meminimisasi resiko bencana.

Burby dan French (1981) menyebutkan bahwa peran perencanaan tata ruang adalah untuk pembatasan pembangunan didaerah-daerah yang rawan terhadap bahaya yang terkait dengan alam hal ini termasuk pembuatan kode bangunan (building code) untuk daerah-daerah yang rawan terhadap bencana gempa bumi dan tsunami.

Building Code pada prinsipnya membangun bangunan tahan gempa, berdasarkan zonasi tingkat kerawanan gempa atau percepatan tanah. Dari zona-zona kerawanan gempa tersebut bangunan akan dirancang bangunan bagaimana yang harus tahan gempa. Dampak dari pembatasan pembangunan di daerah-daerah yang berbahaya akan meminimasi potensi paparan (exposure), pengurangan terhadap kerugian jiwa serta kerusakan harta benda di daerah-daerah berbahaya. Pembangunan yang tidak mengindahkan aspek kebencanaan akan dapat berakibat pada besarnya resiko bencana yang timbul seperti pembangunan permukiman di sepanjang pantai yang berpotensi terkenan dampak tsunami.

RTRW dan perangkat hukum untuk pembangunan tata ruang dimasa depan agar suatu wilayah lebih aman bencana untuk jangka panjang, untuk jangka panjang sampai puluhan tahun ke depan dan diharapkan bahwa pada akhirnya wilayah rawan bencana menjadi wilayah aman bencana. Hal ini dapat dilakukan apabila rencana pembangunan yang dituangkan dalam RT RW dan juga perangkat hukum untuk menyokong hal tersebut dilaksanakan, sehingga secara setahapdemi setahap populasi penduduk yang tadinya berada di wilayah rawan bencana bergeser ke wilayah aman.

Menurut Kementrian Negara Riset dan Teknologi, tsunami tidak mungkin digecah, tetapi mungkin dapat dikurangi resikonya semaksimal mungkin. Tindakan yang mungkin dapat dilakukan yaitu peringatan dini meliputi segala kegiatan yang berkaitan dengan dekteksi dini penyebab tsunami, kemungkinan timbulnya tsunami, prediksi penyebaran tsunami dan penyampaian informasi secara tepat dan akurat. Prosesdur evakuasi meliputi segala kegiatan yang berkaitan dengan pemindahan penduduk ke wilayah yang aman sebelum gelombang tsunami mencapai area yang bersangkutan, termasuk perencanaan jalur-jalur evakuasi yang efisien dan pembuatan bangunan khusus untuk penyelamatan diri (shelter).

Perlindungan pantai meliputi segala yang berkaitan pantai sehingga limpasan energy gelombang tsunami ke arah daratan dapat diminimalkan. Perencanaan tata ruang meliputi kegiatan penentapan wilayah permukiman yang aman dari serangan gelombang tsunami serta pembuatan model tata ruang kampung pantai yang memudahan evakuasi apabila terjadi tsunami namun tetap mendukung aktivitas masyarakat. 


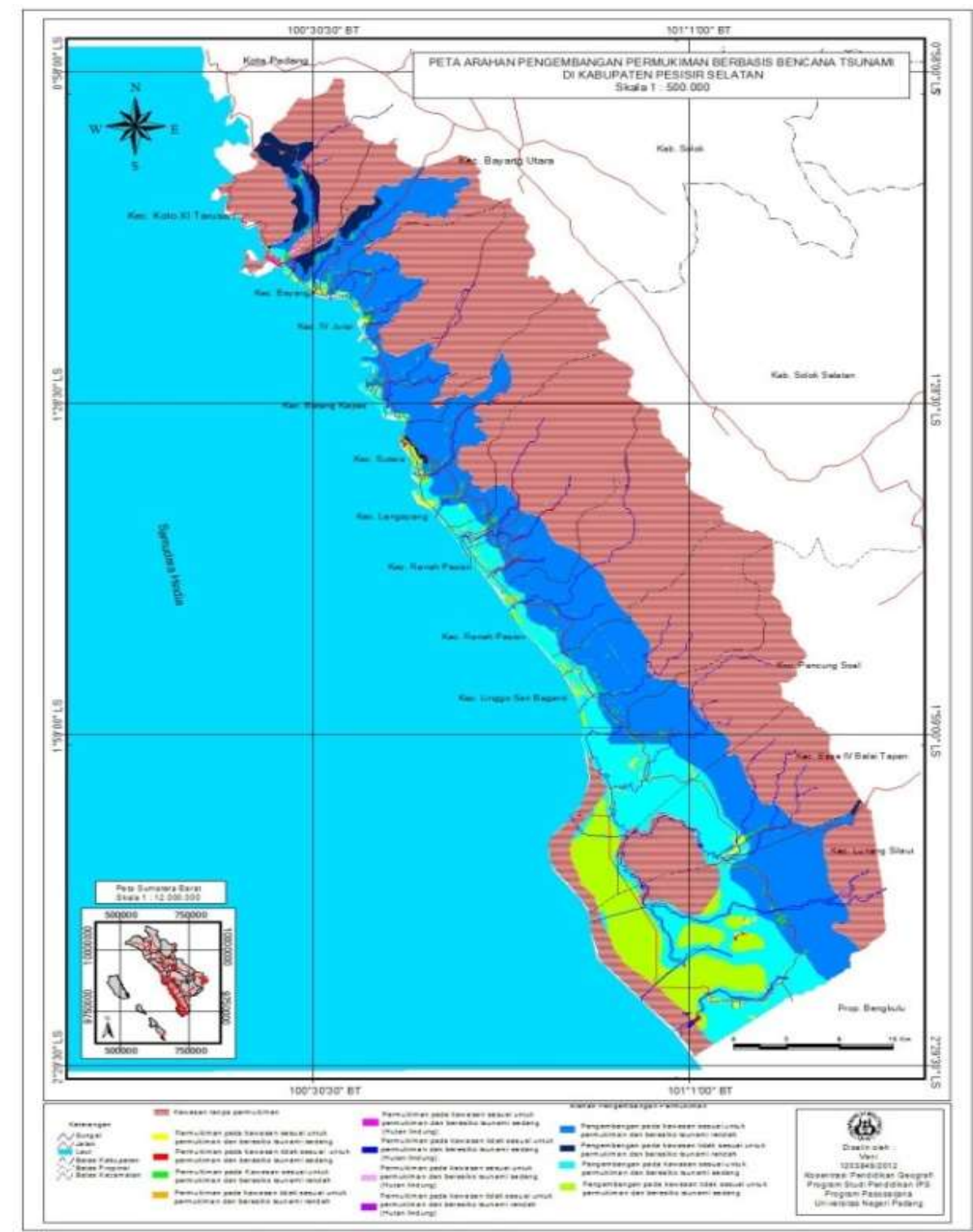

Gambar 4. Peta Arahan Pengembangan Permukiman Berbasis Tsunami Kabupaten Pesisir Selatan

\section{KESIMPULAN}

a. Luas permukiman secara keseluruhan di Kabupaten Pesisir Selatan adalah 8.915,38 ha dengan jarak rumah dari pinggir pantai 0-2 meter. Pola permukiman Kabupaten Pesisir Selatan memanjang mengikuti garis pantai. Luas permukiman yang berada pada daerah dengan resiko tsunami sedang adalah 6084,81 ha dan pada daerah resiko tsunami rendah memiliki luas 2830,57 ha.

b. Pemerintah Daerah Kabupaten Pesisir Selatan disarankan agar segera melakukan pembagian kawasan untuk kesesuaian lahan permukiman dan kawasan beresiko tsunami yaitu : 1)
Kawasan yang sesuai untuk permukiman dengan tingkat resiko tsunami sedang $(946,036$ $\mathrm{km})$, 2) Kawasan yang sesuai untuk permukiman dengan tingkat resiko tsunami rendah (3061,189), 3). Kawasan yang tidak sesuai untuk permukiman dengan tingkat resiko tsunami sedang $(838,710), 4)$. Kawasan yang tidak sesuai untuk permukiman dengan tingkat resiko tsunami rendah $(903,954)$.

c. Arahan kebijakan penggunaan lahan permukiman berbasis bencana tsunami di Kabupaten Pesisir Selatan dapat di prioritaskan pada empat kebijakan yaitu : 1) mitigasi bencana tsunami melalui pembangunan shelter dan jalur evakuasi, 2) Mengetahui zona resiko 
tsunami untuk pengembangan sistem peringatan dini, 3) relokasi Permukiman secara bertahap pada masyarakat yang bermukim pada kawasan yang memiliki resiko tsunami, 4) menyusun kawasan peruntukan lahan untuk permukiman yang berbasis bencana tsunami.

\section{DAFTAR PUSTAKA}

BNPB. 2012. Menuju Indonesia Tangguh Menghadapi Tsunami. BNPB. Jakarta

Dinas Prasarana Jalan, Tata Ruang dan Permukiman (Prasjaltakim). 2013. Kondisi Perumahan Provinsi Sumatera Barat. www.sumbarprov.go.id diakses 14 Maret 2014

Faiz Hadi P, Achmad. 2009. Metode Analytical Hierarchy Process Untuk Menentukan Prioritas Penanganan Jalan Di Wilayah Balai Pemeliharaan Jalan Mojokerto.

Jurnal Aplikasi, Volume 6, Nomor 1, Februari 2009, ISSN. 1907-753X. Program Studi Diploma Teknik Sipil FTSP ITS

Hermon, Dedi. 2012. Mitigasi Bencana Hidrometeorologi : Banjir, Longsor, Ekologi,
Degradasi Lahan, Puting Beliung, Kekeringan. UNP Press. Padang

Hermon, Dedi. 2009 Dinamika Permukiman dan Arahan Kebijakan Pengembangan Permukiman Pada Kawasan Rawan Longsor Di Kota Padang Sumatera Barat (Disertasi). PPS IPB. Bogor

Kabupaten Pesisir Selatan. RTRW Kabupaten Pesisir Selatan 2010- 2030

Rochmasari, Lia, dkk. 2010. Penentuan Prioritas Usulan Sertifikasi Guru dengan Metode AHP (Analysis Hierachy Process). Jurnal Teknologi Informasi Pascasarjana Teknik Informatika Universitas Dian Nuswantoro, Volume 6 Nomor 1, April 2010, ISSn 14149999

Ula, Muhammand dan Azhari SN. 2013 Sistem Pendukung Keputusan Kelompok Penentuan Kelayakan Lokasi Pemukiman. Jurnal IJCCS Vol. 7, No. 1, January 2013 : 89-100

Zulkaidi, Denny dan Petrus Natalivan. 2005. Zoning Regulation And Building Code Dalam Pembangunan Kembali Pasca Gempa Dan Tsunami Di Provinsi Nangroe Aceh Darussallam. Jurnal Perencanaan Wilayah dan Kota,Vol. 16, No. 1, Hal. 1-20 April,2005 